\title{
UNIVERSITY RANKINGS, GOVERNMENT AND SOCIAL ORDER
}

\author{
Managing the Field of Higher Edwation aceording to the Logic \\ of the Performative Present-as-Funter
}

INTRODUCTION: RT*READING GIOBAI, UNIVIERSTYY RANKING IS

The past half decade has seen the emergence of new systems for ranking individual universities against each other on a worldwide scale, of which the most prominent and authoritative is the ordering of university research performance by the Shanghai Jiao Tong University Institute for Higher Education (SJTUIHE. 2007). In many nations, these rankings are widely cited in the media, and in advertising and other communications by universities. In some nations the rankings appear to influence government thinking concerning the ordering of higher education systems, particularly by encouraging policies of concentration of funding and other resources designed to boost the global standing of selected research universities.

As a set of techniques for measuring university performance and ordering universities in relation to each other, global university ranking have roots in longerstanding systems of national university ranking, particularly the annual rankings by the US News and World Report in the United States (USNWR. 2007). At the same time global ranking has gained its sudden importance from the coincidence of two larger policy developments. First, the development of the techniques of the New Public Management (NPM) in the administration of educational systems and institutions, in a period in which neo-liberal perspectives are dominant in government; and in particular the NPM's imagining of higher education as a kind of quasi-economy in which universities compete with each other on the basis of measurable outputs, so that comparative performance can be assessed and used to guide the reform of organisation and the allocation of funds for future activity. Second, the globalisation of higher education; the growing role played by crossborder movements of research, ideas and people in higher edueation and in particular the growing reliance by national policy makers on international comparisons as a means of judging performance; that is, global referencing.

This paper uses a critical perspective to summarise, examine and explain the main systems of global university rankings that have emerged. It focuses on the utilities of rankings as a technique of government that is informed by the perspectives of neo-liberalism and the methods of the NPM. The argument is grounded in the author's scepticism about the desirability and feasibility of the 
ambitious neo-liberal project to 'economise' education (Marginson, 1997). In its discussion of the policy space, the paper draws in part on the theorisations of Pierre Bourdieu, in particular his imagining of a competitive university "field" that is structured by a polar opposition between elite research universities and vocational mass institutions (for further discussion of Bourdieu's conception of field see immediately below).

At the same time the paper does not adopt a full blown 'Bourdieu-ian' perspective. It can be argued that Bourdieu's summation of human identity and behaviour under the label of acquired "habitus" (Bourdieu, 1984), while again suggestive, underestimates the scope of human agency in imagining alternatives and transforming social structures: for more of this kind of critique of Bourdieu's 'structuralist' bias see Marginson (2008a), and also the work of Arjun Appadurai (1996) on global agency. Arguably Bourdieu is at his best when describing the endogenous dynamics of structures, to the extent that these dynamics are independent of human agency; and his insights there are helpful in exploring the structure-building neo-liberal project, for example the manner in which constructed markets work. Nevertheless neo-liberalism and the NPM are also designed to change objectives, values and practices. To more fully understand the effects of university rankings in human and governmental behaviour, as well as more on the scope for resistances and alternatives to the dominant neo-liberal practices in higher education, we need to look also beyond Bourdieu to many others: for example Rose (1999) and other post-Foucaultian social theorists; and various critiques 'from below' of globalisation in higher education, for example the collections by Burbules \& Torres (2000), and Rhoads \& Torres (2006). This larger zone of criticism and discussion will not be explored in detail in this paper which for reasons of length and focus concentrates on global university rankings.

\section{MODLIIING UNIVERSITY PERFORMANCE}

\section{Bourdieu's theorisation of the "field" of higher education.}

In the last half century the only major social theorist who has conducted a sustained investigation into the dynamics of higher education is Pierre Bourdieu $(1984: 1988 ; 1993 ; 1996)$. Bourdieu develops the notion of a field of power, such as the university field or field of higher education, "understood as a space, that is, an ensemble of positions in a relationship of mutual exclusion" (1996, p. 232). A field of power is a social universe with its own laws of functioning. The field enjoys a degree of autonomy, to the extent that it holds off external determinants and is driven by its own internal logic. Within the field of power, agents (in higher education both institutions and individuals are agents) are locked into competition for resources, status or other objects. In this competition there is inter-dependency between the prior positions of agents within the hierarchy - their starting positions in the competition, the resources and networks at their command, and so on - and the 'position-taking' strategies they select. Bourdieu describes the position-taking activities of agents as the "space of creative works" (p. 39) but this is not an open- 
ended free-wheeling creativity. "Fvery position-taking is defined in relation to the space of possibles which is objectively realised as a problematic in the form of the actual or potential position-takings corresponding to the different positions" (Bourdiet. 1993, p. 30). In other words, only some position-takings are possible: and the moves of agents tend to correspond to their starting positions: so that within a social order people tend to make moves that tit with their own expectations, their identity and their senses of possible is possible and likely. The possible positions that agents can adopt are identitied by them as they respond to changes in the settings of the competition game. and also to the moves of others within that game. Agents have a number of possible "trajectories". that is the succession of positions occupied by the same agent over time: and emplos semiinstinctual 'strategies' to achieve those trajectories. In doing so agents respond in terms of their "habitus" which is the mix of beliefs and capabilities they have acquired through their upbringing and their past experiences of social competition (pp. 61-73). For example both the habitus and the prior position in the hierarchy of universities tend to shape the degree to which individual university leaders use strategies that are characteristic of elite rescarch universities.

For Bourdieu the field of higher education is structured by a polar opposition. At one end there is the sub-field of restricted clite production. At the other end is the sub-field of mass production tending to commercial production. Each sub-ficld has its own distinet principle of hicrarchization. In the aristocratic elite universities. where the high value products are immersed in knowledge and power and shaped as tools of advantage, the principle of therarchization is that of cultural status and is autonomous and specific to the field. In the mass or popular institutions. hierarchy is shaped by economic capital and market demand. and the institutions are heteronomous; though from time to time mass institutions renew themselves by adapting ideas from the elite sector. Between these two sub-fields lie a range of intermediate institutions combining the two opposing principles in varying degrees.

As noted. Bourdieu"s theorisation has been enticised for his failure to overcome, despite his own strenuous efforts. especially in Distinetion (1984). the dualism he creates between structure and agency and the manner in which his notion of agency becomes trapped on the structure side. More specifically, the picture of higher education governed by universal relations of competition is open to eriticism, as it neglects the prevalence also of gift relations and public goods. for cxample in scholarship and research (Kenway, et al., 2006: Marginson. 2007a. Marginson. $2007 \mathrm{c}$ ). Much of Bourdieu's underlying research took place in pre-1968 French institutions, prior to the fuller growth of mass higher education. and prior to policy neo-liberalism and contemporary globalisation. Yet despite these limitations. Bourdieu's idea of the field of higher education. if not a satisfactory general theory of higher education, is in some respects powerfully explanatory of the contemporary dynamics of competition in that sector. It seems that in a period in which inter-university competition has taken a more powerful. pervasive and more specifically economic form. Bourdieu's notion of the lield of higher education. which like all his theorisations tends to miversalise social relations instrumental to capitalist society, comes into its own. The Bourdicuian polarity hetween the sub- 
field of elite institutions and the sub-field of mass-commercial institutions can readily observed in national higher education systems (Naidoo, 2004) where it helps to explain inter-institutional tension and differentiation. More remarkably, perhaps. Bourdicu's 1960s polarity and his principles of hierarchization, especially in the elite sub-ficld, also illuminate the emerging global competition.

\section{Ner-hihalondering of the field}

If competition in higher education has long-standing social roots as Bourdieu argues. its contemporary form as a market derives primarily from the evolution of government. Most of the world"s higher education systems have been affected by neo-liberal policy and its financial and administrative technologies collated in the New Public Management (NPM). The passage of those policy ideas between countries has moved faster in the present more global era which is characterised by instantaneous communications and complex data transfer, cheaper air travel and more intensive people movement between national governments and between universities in different countries. There has been a perceptible increase in the tendency for national policies and the practices of institutional management to converge (Marginson \& van der Wende. 2007); and numerous studies, supportive and critical, attest to the impact of the New Public Management in system organisation and institutional culture (c.g. Clark, 1998; Rose, 1999: Marginson \& Considine, 2000; Musselin. 2005; Henkel. 2005; Rhoads \& Torres, 2006). As is now well known the NPM imagines national systems as economic markets and unversities and other higher education institutions as firms driven by desires for economic revenues and market share, not by teaching, research and service as ends in themselves. The NPM noms higher education as a state-steered competition. national systems as a mixture of public and private institutions, and institutions as an executive-steered competition between academic units and personnel. Social demand is meant to be regulated by tuition prices, and institutions engaged in marketing, customer focus, entrepreneurship and research programs advocated by policy researchers who argue that research is or should be driven by industry requirements and government-determined research priorities rather than the curiosity of researchers themselves (Gibbons et al., 1994; Nowotny, et al., 2001). At the same time the neo-liberal era in higher education is an era of utilitarian performativity as Lyotard (1984) remarks, in which competition is serviced by performance measures, output-based funding, measures of economic value, tests of relevance and impact, and relations with funding agencies based on contracts, accountability and audit.

NPM reforms drive towards liscal efficiency, global trade and competitiveness and more effective systems of nation-state control of universities and their work. The double move, the deregulation of the university-as-firm and over-regulation of academic output as performance, creates a complex mix of tendencies to autonomy and heteronomy in which the older freedoms of basic research and scholarly 
agency are not so much abolished as reworked, becoming more mobile. multiple. fragmented, fragile and contested (Henkel, 2005; Marginson, 2008b).

This historical project of neo-liberalism and the NPM, that of recasting the field of higher education as a performative market of competing universities-as-firms, in turn generates the need for two innovations in policy technology site-specific to higher education. The first innovation is a plausible and coherent model or models of the ideal university-as-firm. The second innovation is a plausible mapping of the higher education field in the form of a hierarchy of institutional performance, that can be represented as the outcome of market competition. These two policy innovations are inter-dependent. The ideal model functions as a template against which institutions of higher education are measured and ranked.

Idealised models. Across world-wide higher education there are many different combinations of mission, structure and organisational culture, each set associated with distinctive traditions and models nested in national contexts, historical identities and conditions. In the 'Westminster' countries (UK. Australia, New Zealand) systems combine university autonomy and public/private investment with explicit national steering. The Scandinavian university combines high and socially equitable participation, research culture and university autonomy with state investment (Valimaa, 2004; 2005). The German-style university opts for elite participation, research culture and state administration. The classical Latin American public university as at the University of Buenos Aires combines high participation, scholarly culture and a central social and political role in building the nation-state. The emerging science universities of East and Southeast Asia. including China, Taiwan, Korea and Singapore are fostered by state investment and in Singapore are explicitly designed to secure global competitiveness. India has developed a unique model of technological and business-focused institutions combining high quality with commercialism. Beyond the research university are strong vocational sectors in Finland, Germany (the Fachochschulen), France: other vocational and community-based programs; and a wide range of for-profit providers, online institutions and institutions with single-specialisms.

Nevertheless, in the generic policies of the NPM, exemplified by the checklists used by the World Bank in its lending programs in the developing world, there are two favoured models against which institutions around the world are readily judged. These models are quite different, but one (that of the ideal research university) enjoys greater status in most circles than does the other. Given the weight of the United States in the global political economy and culture, and in the higher education sector itself, it is unsurprising that both of these models have been derived primarily from the American experience. The models are:

- The idealised research university. Emphasises research and graduate studies. excellence and prestige. Entrepreneurial (Clark, 1998). Tied to business and the knowledge economy. Competes for students and funds. Internationally oriented. Achieving a growing autonomy via financial diversity, including tuition and 
philanthropy. The US Ivy League private universities are closest to this model in the real world. In some respects the practices of these institutions diverge from the model - for example their funding (especially in research) is more statedependent than the NPM ideal would suggest; they do not evidence a strong dynamic of responding to the preferences of the student consumer; and their support and prestige rest to a surprising extent on lobbying politics in Washington, rather than market demand pure and simple. Nevertheless, the real life Ivy League universities, which are powerful institutions, are close enough to the idealised research university in the model to confer on that model exceptional prestige and therefore a tremendous potency in shaping notions of good practice across the world.

- The idealised institution of mass vocational higher education. Focused on training for business, computing, and mass professions such as health and education. Accountable for immediate vocational relevance. Expansionary of student numbers, sites and market share; and in the case of fully commercial institutions driven by profit. Marketing-driven. Spare and efficient with no 'frills' such as research, libraries or academic freedoms. 'Customer'-focused using performance management of staff and quality assurance. Mass vocational higher education, tending to commercialisation, has a mixed record around the world but in the US has become embodied in corporations raising significant equity funds, including the Apollo Group, parent company of the University of Phoenix. Phoenix is the largest private university in the USA and has spread to a dozen countries.

These two models are idealised manifestations of each of the two sub-fields identified by Bourdieu, confirming the relevance of his notion of the field.

The mass vocational higher education model is also not very far from the practices of commercial cross-border education in the UIK and Australia, where mostly non-profit universities provide for-profit education of foreign students at home or in transnational campuses abroad. We find this kind of commercial international education even in certain research-intensive universities. While on one hand those institutions position themselves as elite providers in relation to domestic students; on the other hand, in the global market they position themselves as mass providers engaged in an expansionary form of education designed to maximise revenues in true capitalist fashion. Typically, the dominant form of cross-border program is the standardised high volume production of programs of medium quality business education (for more discussion see Marginson, 2007b).

Of course there are other possible 'American models' in a national system that is a by-word for structured diversity: the liberal arts college, the state universities and four year institutions, and the community colleges. Most US enrolments are in the public sector, including the University of California system and the land grant and other public flagship universities. But the lvy League private institutions have the highest status; while in neo-liberal circles the US public institutions are seen as ambiguous institutions, inferior to the commercial sector as vehicles for expanding mass education; subsidy-heavy, often research-thick, supply driven and inflexible. 
Rank ordering the field on the basis of performance. National rankings of universities date back to the 1920 s and a long established method of creating a status hierarchy, apparently based on merit, which can be deployed for the purposes of annual "consumer guides" to student choice; a practice that has become entrenched more in some countries more than others. Now we have global rankings, the listing of a university hierarchy on a world-wide scale. which began in 2003. University rankings have proven an effective means of normalising higher education as a market of competing institutions, in which "quality" is grounded in 'performance' and equated with market power. Global university rankings translate that notion of competitive market onto the global plane, while quictly hustling from the stage the more cooperative elements in inter-institutional relations, for cxample the free exchange of research information. Rankings create a compelling picture. Apparently, they summarise the whole university world in a single table. Everyone wants to know which universities and which nations are regarded as "better" or 'worse' and whether their institutions/systems are rising or falling. Rankings give such judgments a telling kind of authority. At the popular level this authority is sustained regardless of the many technical and methodological issues, and the omissions and biases, inherent in any and every ranking system. Thus the ranking process combines the neo-liberal imaginary of education as a market. and the practices of competition and performance measurement established by the NPM. with a compelling simplification that explains a lot by means of a little.

In global rankings systems the leading institutions are normally those US and UK (principally American) research universities that operate in the elite sub-field of the global market and congruent with the first idealised model listed above. The idealised mass vocational university also plays a role in some rankings systems. albeit a subordinate role. Let's look more closely at the conditions that made global ranking of universities possible and perhaps (in the eyes of some) necessary.

Hierarchical global comparison of universities has been made possible by a particular conjunction of discursive conditions. The development of a global performative hierarchy was foreshadowed in the practices of hierarchical ordering and exclusion traditional to higher education, in credentialing and knowledge cultures: informal status ranking has long been part of thinking in many countries. As noted some of the groundwork was laid by global communications. trade in education and the NPM; and also by the world-wide organisation of science and research and the growing dominance of English as the one global language of research. Comparisons of national performance in education have been legitimated by the widespread use of cross-country comparisons in economic policy, in which the nation-state is understood as a competition state and government performance is according to whether the nation is seen to be rising or falling on the global plane. More specifically, university rankings have roots in the nomative methods of comparative education and development education, particularly the pervasive comparisons of national policy performance by the OECD (2006) and World Bank.

Global university rankings have gripped the attention of higher education institutions, governments, media and public throughout the world. They have quickly secured a major influence in the definition of the field of higher education. 
University rankings seem to tap into strong desires for rank ordering as an end in itself, without much regard as to what the rankings measure, which objectives or activities of higher education they incorporate and which models of institution they embody, whether they are well grounded in observation and logic, whether their use has constructive effects. Strikingly, institutions are often rank ordered even where differences in the data are not statistically significant. League tables rule.

Rankings more precisely identify a global hierarchy of leading universities, a hierarchy which varies according to ranking system, but not much at the very top; and hence enable league tables of national system performance, for example the proportion of universities from each nation in the top group of universities. Rankings always pose the question: 'How can our university/nation perform better?' University rankings entrench understandings of the field of higher education in 'Bourdieuian' terms - as competitive, a site of struggles for position, in which the strategic options are shaped by prior position - while more deeply legitimating cross-border comparison. University rankings also entrench understandings of the field in 'Lyotardian' terms, as a contest in performativity in which performance is measurable and visible and its utilities are determinant.

Here the definition of 'performance' is all important. Rankings systems appear to 'evaluate universities as a whole' (van Dyke 2005, p. 106). But of course no rankings system can cover all purposes of higher education from the point of view of all actual or potential stakeholders: the outputs are multiple and complex, some are potentially in tension with others, not all are open to numerical measurement; and one key area, the quality of teaching and learning and the "value added' during the educational process, eludes comparative measurement (Dill $\&$ Soo, 2005). In composite ranking systems across multiple domains, or more than one numerical measure within a domain, the weightings are both largely hidden and essentially arbitrary. All ranking systems encompass the needs of some stakeholders better than others. Usher \& Savino (2006) examine 19 league tables and university rankings, noting they are driven by varied purposes and definitions of quality. The point is not that this heterogeneity allows rankings to be dismissed as relative. The composition of each ranking system matters, because it generates specific effects.

The remainder of the chapter will discuss national rankings in the United States; the principal global rankings systems now in use, those prepared by Shanghai Jiao Tong University Institute of Higher Education (SJTUIHE, 2007) and the Times Higher Education Supplement (THES, 2006) review the policy responses to rankings; and consider their effects in a little more detail; before concluding.

\section{RANKINGSSYSTEMS}

\section{National Rankings}

National rankings date back to the 1920 s in the United States. Most countries with large higher education systems have rankings of one kind or another. Countries with rankings devised by newspapers and magazines include China and Hong Kong China. Japan, India, the Ukraine, Romania, Poland, Portugal, Italy, Spain, Germany, 
Sweden, Switzerland, France, UK. USA and Canada. In Chima, Japan. Australia. Kazakhstan, Slovakia, Romania, Russia, the Ukraine. Germany, Spain. Switzerland. the UK and Canada rankings have been initiated by universities. protessional associations or other organisations. In Thailand, Malaysia. Pakistan. India, Kazakhstan. Korea, Tunisia, Nigeria, the Netherlands, the UK, Brazil and Argentina rankings have been instigated by ministries of education, grants councils or accreditation agencies (Salmi \& Saroyan. 2006). Usher and Savino (2006) review rankings complied in Australia (Williams \& van Dyke, 2006): Canada: China. with several rankings systems (Liu \&d Liu. 2005), and Hong Kong; Gemany: Italy: Poland: Spain; the UK with its four newspaper systems, and IISA.

US News and World Report rankings. The ammal LS News and Horld Report rankings are worth noting here, given the world-ivide importance of higher education in the United States. The USNWR exercise has played a key role in legitimating global rankings: and given the global leadership exercised by the American sector this ranking also acts as a de lacto global ranking of sons. Most part national rankings consist of a single table but in the USA and Canada higher education institutions are divided into groups according to mission and characteristics, creating a set of mini league-tables. The $U S$ News and llowd Report survey focuses principally on aspects of institutions seen to contribute to the quality of teaching and the student experience, servicing the national student market which is underpinned by government-backed loans and university tuition scholarships. The categories are drawn from the 2000 classitication by the camegre' Foundation for the Adrancement of Teaching (USNWR. 2006. p. 81ff). The leading grouping is the "national Universities". 248 universities ( 162 public and 86 private) with a range of fields of study. degrees to doctoral level and mostly research intensive.

In the category of National Universities 25 per cent of the index is comprised by a survey of "undergraduate acadenic excellence" sent to university presidents. provosts and deans of admissions. Two items each constitute 20 per cent: student retention and graduation rates; and 'faculty resources' which rewards small classes, high academic salaries, high academic qualifications and a high proportion of staft full-time. Student selectivity at entry, a proxy for positional status, is 15 per cent. The lesser items are spending per student ( 10 per cent). the proportion of alummi who donate to the institution (5 per cent), and the graduation rate after controlling for spending and student aptitude (5 per cent) (USNWR, 2006, pp. 77-79). These details have become very signilicant. Over the years institutions have leamed to modify and target their behaviour so as to maximise their $U / S$ Lens position. This has also had specific effects perverse from the viewpoint of the publie good. For example, in order to maximise their USNWR seore, institutions manipulate the administration of student entry so as to pluralise entry method and reduce the number of students following what is seen as the "nomal route of entry. This allows the institutions to raise the (apparent) lowest score that a student needs to enter so it appears as more selective. More generally. institutions seek to compose 
their student body as selectively as possible, not just in appearance but in reality -. maximising both student scores and also application refusal rates, each of which comes into play in the USNWR tables. This is despite the fact that student entry scores tend to be correlated with social advantage, so that the more academically selective the student body, and more it is also socially selective and tends to underrepresent students from poorer backgrounds. A study of American enrolment management" by David Kirp also notes the growth of merit-based student aid at the expense of needs-based student aid. Again, the purpose is to attract an academic elite rather than a socially representative colort so as to lift the UNSWR performance on the indicators of student selectivity, student retention and graduation rate indicators (Kirp, 2004). These are telling examples that point to the tendency of competitive rankings to install socially regressive behaviours at the level of the individual university, that subtract from the common social good.

\section{The Haw Tong llorld Universing Ronking}

The world-wide university ranking lirst issued by the Shonghai Jian Tong Unicesing Institule of Higher Educalion (SJTUIHE) in 2003 was supported by the Chinese government. which wanted to assess the research performance of Chinese universities according to intemational standards in order to inform strategies designed to lift the competitive position of science and technology in China.

Institutional rankings are issued annually and in February 2007 rankings in five broad disciplinary fields were released. The Jico Tong group argues that the only data suthiciently reliable for ranking purposes are broadly available and internationally comparable data of measurable research performance (Liu \& Cheng, 2005. p. 133) and this is the sole focus. Research performance is measured using a composite index with weights given to the different criteria. The index is primarily driven by academic publication and citation, mostly in science-based disciplines with some attention to social sciences and humanities: 20 per cent citation in leading journals as listed by publisher Thomson; 20 per cent articles in Science and Vumre: and 20 per cent the number of Thomson/ISI HiCi' researchers in the top 250-300 in their ficlds on the basis of citation (ISI-Thomson, 2006). Another 30 per cent is determined by the winners of Nobel Prizes in the sciences and economics and Fields Medals in mathematics, based on the location of training ( 10 per cent) and current employment (20 per cent). The remaining 10 per cent is determined by dividing the above total by the number of academic staff. The separate discipline rankings fall into tive categories: natural sciences and mathematics, engineering/ technologies and computer sciences. life and agricultural sciences, clinical medicine and pharmacy, and social sciences. While the same broad schema is followed in the determination and weighting of criteria, there is some variation by discipline due to publishing conventions (SITUIHE. 2007). The Jiao Tong index focuses on real outputs not subjective assessments of performance or reputation, except that decisions on Nobel Prizes/Fields Medals are submission based, so that science and scholarship are not the only determining factors. 
The SJTUIHE rankings value large comprehensive universities with strong research performance over a broad range of science and few research inactive staff. The rankings favour universities from English language nations because English is the language of research, non English language work is published less and cited less in journals distributed on a world-wide basis; and favour universities from the USA because Americans tend to cite Americans (Altbach, 2006). Jiao Tong research performance is dominated by English speaking nations, with 71 per cent of the world's top 100 research universities in 2006 . The United States has 17 of the Jiao Tong world top 20, led by Harvard, and 54 of the top 100. A university's number of Thomson/ISI 'HighCi' researchers directly and indirectly drives performance across much of the index. HiCi researchers are overwhelmingly concentrated in the USA, with 3835 in June 2007 compared to the next best. the UK with 443 (Thomson-ISI, 2007). On the world scale the distribution of mainstream research capacity is overwhelmingly lop-sided. In 2001 US scientists and social scientists published 200,870 papers in major journals. Indonesia with two thirds the U.S. population created 207 papers (NSB, 2006).

In the Jiao Tong rankings the principle of hierarchization at work is essentially that of Bourdieu's sub-field of elite institutions. That is, the criteria for success are the volume and quality of research knowledge, cultural values that are autonomous to the field of higher education itself and defined and controlled by its practitioners. The doubt is where the boundary of the sub-field falls, which institutions lie within the global elite. This is impossible to resolve in technical terms using Jiao Tong style calculations. When institutions are ordered according to a single set of numerical indicators, differences are expressed in degree not in kind. Nevertheless, by naming a top 100 with place-by-place rankings and an overall top 500 the SITUIHE provides a two tier descriptor of the global hierarchy based on arbitrary place-divisions. Further, given that it is as significant to be excluded from the Jiao Tong top 500 as to be ranked within it, the SJTUIHE has constructed a de facto hierarchy across the entire sector.

The SITUIHE group (2007) emphasises that this is not a holistic ranking of all aspects of universities, for example teaching quality, only elements of research. But by arranging universities according to research status, the Jiao Tong rankings construct what becomes a reputational hierarchy. Harvard becomes understood not as leading research site but leading university. Market research and anecdotal evidence from educational agents indicate that the rankings feed into student choice-making, not just of doctoral programs, where research capacity is instrumental. but first degree and Masters programs as well. And Jiao Tong performance has quickly become an indicator of national status. At this point the Jiao Tong rankings. however soundly based in recognised metrics, start to function just like all reputational rankings. A hierarchy based on reputation, once established, recycles its own conditions of possibility. Known university brands generate halo effects. They attract ever more money and talent so that their measured performance continues to climb and their stellar reputation is continually reproduced. Newcomer institutions tend to be blocked, regardless of talent or effort unless, like research 
universities in Singapore and China at present, they are the subject of strategies of state investment on a spectacular scale.

\section{The Times Higher Glohal Ranking}

The first Times Higher Education Supplement 'World University Rankings' were published in 2004. The aim is a summative, holistic ranking of university "quality". in entering the rankings game the ultimate purpose of the Times was to sell publications and data though a secondary purpose might be inferred from the manner of the exercise, to elevate the global position of British universities.

The Times Higher also uses a composite index, one that is more heterogeneous than the Jiao Tong. Half of the index is grounded in present reputation, 40 per cent comprised by a survey of academics ("peer review") and 10 per cent by a survey of "global employers". There are two internationalisation indicators: the proportion of students who are international ( 5 per cent) and the proportion of staff ( 5 per cent). Another 20 per cent is fixed by the student-staff ratio, a quantity measure intended as a proxy for teaching 'quality'. The other 20 per cent is comprised by research citation performance per academic staff. The Times issues an annual list of the top 200 universities in order of merit, plus rankings by institution in natural sciences, engineering and IT, biomedicine, social science and arts/humanities (THES, 2006). The 'Times tables' are open to methodological criticism in relation to most parts of the index. For example, in 2006 the survey of academic 'peers' gathered a response of just I per cent from 200.000 e-mails sent worldwide, and the pool of responses was weighted towards the UK and Australia. Teaching quality cannot be assessed using student-staff ratios. The student internationalisation indicator rewards student volume without accounting for the quality or quantity of applications.

In composing a global market the Times Higher is more ambiguous than the Jiao Tong. Leaving aside composition bias, the 50 per cent of the index measuring comparative reputation reproduces the established global hierarchy. Much the same research intensive universities lead the Times Higher as lead the Jiao Tong, though below Harvard the order is somewhat eclectic. The effects of elite reputation are reinforced by the 20 per cent based on research performance. At the same time, reputation is affected by more than just research performance. Compared to the Jiao Tong, the Times Higher elevates well known institutions in national systems especially those in national capitals, so that the leading Chinese universities do very well in the Times Higher. It is likely its reputational indicators are also influenced by the heavy marketing by some Australian and UK universities in the cross-border student market. Likewise the internationalisation of students indicator rewards institutions active in the cross-border student market; and because it is a quantity indicator, it unambiguously rewards a mass orientation within that market. Strictly speaking, the Times Higher rankings reward a university's marketing division as well as its researchers. The Times Higher combines, in a more erratic fashion than the fiao Tong. both of Bourdieu's principles of hierarchization. Universities that lead the elite sub-field are in a dominant position, and these are 
accompanied also by certain institutions that draw strength from a role in the crossborder mass education sub-field, and a handful that have particularly strong vocational reputations. The mass/vocational subfield is less prominent than the elite research subfield. The result is a less coherent order in which the hierarchy of research universities is under-determined by the hierarchy of universities that provide mass cross-border education or emphasise vocational mission.

Below the top 40 places the Times Higher is also a volatile hierarchy. Many institutions experience sharp rises and/or falls. For example between 2004 and 2006 the University of Geneva in Switserland moved from outside the top 200 to 39. Fudan University in China was placed successively at 195, 72 and 116 . the University of Seoul in Korea jumped from 118 to 63, and RMIT University in Australia moved down from 55 to 146. Many other examples can be cited. These fluctuations do not appear to be performance related, being largely random effects consequent on weaknesses in data gathering and changes in data collation methods.

The Times Higher ranking also generates more particular effects arising from uncorrected composition bias. The UK and Australia do too well. The UK has 15 per cent of the GDP of the USA but half as many universities in the Times top 100 in 2006: UK 15, USA 33. (The USA had 54 research universities in the Jiao Tong top 100). In 2006 the UK had two of the Times Higher top three and Cambridge UK almost closed the gap on Harvard. Yet the Harvard faculty is cited at three and a half times the rate of Cambridge and has greater world-wide prestige. Australian universities perform exceptionally in the peer survey of academic staff and student internationalisation indicator, thereby benefiting from both Bourdieuian principles of hierarchization. In 2006 the Australian National University was ranked by the 'academic peers' as ahead of Yale, Princeton, Caltech. Chicago, Penn and UCL.A. Despite a relatively poor citation rate and moderate staffing ratios Australia had 13 of the Times top 200, making it the third strongest national system, ahead of Japan. Canada, Germany and France. The prominence accorded to the Australian institutions by the Times is consistent with their leading role in international marketing - where Australia is a successful exporter - but is inconsistent with their weaker role in research and hence in the elite subfield. Thus the Times exaggerates also the overall reputation of the Australian institutions. The Times tables have been much criticised, particularly in Western Europe. Nevertheless, with the Jiao Tong, though less effectively, the Times Higher shares the ordering of the global market.

\section{POL.KY EHTITS OF GI,OBAI, RANKINGS}

\section{General policy effects}

Outside the USA (where only the US News ranking is important) Jiao Tong and the Times Higher have already secured visible effects in behaviours and policies. Rankings function as a meta-performance indicator. The criteria used to determ ine each institution's position in the ranking system become meta-outputs that each institution places on priority, so that rankings begin to define "quality". In the world 
of the Jiao Tong rankings, "quality' means scientific research and Nobel Prizes, not teaching or community building or solving local or global problems. In the world of the Times Higher, "quality' is reputation, larger staff-student ratios, research, and international staff and students; and is partly fostered by marketing. It seems that institutional leaders, and governments, have been given their marching orders. By shaping university and system behaviours, while standardising the definitions of outcome and output, rankings begin to decide university mission and the balance of activity, externalising part of university identity. This shift from autonomy to heteronomy is important, carrying with it serious problems for the trajectory of higher education in many countries, but is not universal. Heteronomy scarcely touches institutions at the very top which remain masters of their own identity. The elite sub-field if anything cuts a stronger figure in the world, though it has become a smaller group: outside the USA and UK the status of elite institutions at the national level has now been partly displaced by that of the global super-league.

The two rankings systems have triggered a flurry of marketing by the successful institutions, and the common desire to lift performance, either by changing what is measured or changing how it is interpreted. Within universities they encourage the concentration of internal resources in the principal science-based fields, greater separation of teaching and research, and the refashioning of research programs in terms of specific indicators such as ISI journal publication. Rankings encourage those strategic initiatives within institutions that lift measured performance in the short term and medium term; and they tend to discourage initiatives in mission and organisation, curriculum, pedagogy and research without implications for rankings performance (the opportunity cost is increased). In inculcating the model of ideal performance that underlies them, rankings standardise the sector over time and reducing the diversity of mission and outputs. The normalising effects are maximised when there is only one or a very small number of rankings systems. The more diverse and multiple the measures, the less potent the effects of each.

At government level, ranking has triggered the desire to see more universities in the upper echelons of the tables, as a signifier of national success and potential in the policy context of a global knowledge economy. In turn this has created or further encouraged policies to concentrate a higher proportion of research activity and resources in a selected group of leading universities and to attract and hold top flight researchers. Singapore has set out to attract high quality academic expatriates with US-level salaries. China and Germany (van der Wende, 2007a) have selected groups of universities given special additional research status and others, such as Australia and the UK, are talking about it. Everywhere the goal is to replicate the global attractiveness and impact of the American doctoral sector, though this is difficult to do without American economic, technological, and cultural power.

The intensified competitiveness consequent on rankings has the potential to trigger an increase in levels of national investment in research and is likely to boost science-strong institutions. But it contains negative potentials for many others. On the whole vocational education is downgraded, as it is largely unable to contribute to performative global competitiveness, though some research universities with a vocational twist, for example in India and the Netherlands, have prospered in the 
Times Higher ranking. Research universities outside the Anglo-American norm. such as the high participation national universities of Latin America. are placed under increasing pressure to remake themselves. All universities have stronger incentives to put performance ahead of social aceess. More generally. a rankingsbased reputational race is a race that few can win. even research universities. When positional competition is intensified and everyone stands on tip-toc. no one can see better. "The race gets longer for the same prize" (Hirsch. 1976. p. 67).

A principal concern in many countries is the bias in favour of knowledge in English. Although English is the only global language of research publication it is not the only language of thought. The exclusion of work in other languages is most problematic in the humanistic social sciences and humanities arts. This problem have generated a range of responses in the non English-speaking world. from lobbying for the inclusion of non-English publications in rankings systems. to the creation of separate language-based rankings lists, to a rejection of rankings.

\section{European Policy Responses}

In Europe the accelerated research race has generated not just national but multilateral actions. Leiden University in the Netherlands has led the formation of a League of European Research Universities. The European Union plans a combined European Institute of Technology (van der Wende, 2007a: 2007b). There has also been a range of responses centred on comparison itself: development of a comprehensive comparison of teaching and research based on survey data. by the Centre for Higher Education Development (CHE) in Germany: construction of publication and citation metrics by a Ieiden University group; and negotiation of a typology of European institutions enabling a more diverse set of comparisons.

The Cente for Higher Education Deletopment (cHE) comparisms. The Centre for Higher Education Development (CHE), located in Gutersloh in Noth RhineWestphalia in Germany, compares the programs of universities. in conjunction with the German Academic Exchange Service and the publisher Dic Zeit. CIIE. surveys 130,000 students and 16,000 staft in almost 250 institutions. collecting data on student experiences and satisfaction. and academic recommendations on the best locations in each field. It focuses on 36 academic subjects each offered by a substantial number of institutions. It supplements the surveys with independent sources comprising one third of the data base. No data are taken from institutions. CHE ranks departments according to each separate indicator of academic and service quality, assigning them to top third. middle third or bottom third of all institutions. It refuses to integrate the indicators into a single weighted indicator either for each subject or each institution. It states that there is no "one best university" across all areas, and "minimal differences produced by random fluctuations may be misinterpreted as real differences" (CHE. 2006).

ClIE notes also that students have heterogeneous preferences as to mission and purpose. Accordingly, the CHE data are made available to prospective sludents and 
the public free of charge via an interactive web-enabled database. Any person can interrogate this data base by investigating the comparisons in their own chosen disciplines and services, thereby creating the weightings and rankings themselves.

Thus CHE dispenses with holistic rank ordering of institutions in league tables. avoided problems of arbitrary weighting and composite indicators and admits multiple purposes into the comparison, and has shifted the normative power of the comparison process from the ranking agency to the user of higher education. Its approach lacks the discursive potency of a single league table but the data are more useful to more people. Significantly, the approach has proven highly successful with public and students, governments, and academic experts on rankings systems (van Dyke, 2005; Salmi \& Saroyan, 2006; Usher \& Savino, 2007). The CHE data collection has been extended to Switzerland, Austria, the Netherlands and Flanders, the Dutch-speaking portion of Belgium. "The CHE ranking system is thus well positioned to develop into a European-wide system" (van der Wende, 2007b).

Oher dewomments. The Centre for Science and Technology Studies (CWTS) at Leiden University in the Netherlands is preparing a new ranking system based solely on bibliometric indicators that it has developed (CWTS, 2007). This takes in the 400 universities with the largest number of academic publications, covering the output of at least 600 active researchers in each of those universities. The CWTS has developed range of indicators. Its favoured approach is ranking by average impact as measured by citations per publication, modified by normalisation for academic field, and controlled also for institution size, thereby addressing two weaknesses in the Jiao Tong approach. The Leiden group has also dispensed with the Nobel indicators used by Jiao Tong. The result is an arguably more accurate comparison which like the liao Tong, entrenches the research university market.

A comprehensive typology of European institutions is also being developed (van Vught. et al., 2005; van der Wende, 2007b). This typology is made up of a number of parallel schemes each based on a different characteristic: size of institution, legal status, type of education (degrees offered, range of disciplines), student and staff profiles. activities in research and innovation. The areas of teaching, lifelong learning. innovation, knowledge transfer and local and regional engagement all require further work (van der Wende, 2007b). Europe institutions are being asked to specify their own missions, consistent with autonomy. It is unclear whether once the typology is established institutions will be free to redefine their category.

\section{CONCIISION: TIIE PIRIORMAIIVI PRISINT-AS-FUTURT}

It is likely that a more plural set of indicators and of rankings will develop; with greater specialisation in relation to mission and function, as indicated by emerging discipline indicators and citation metrics. especially in Europe. However it is by no means clear that the normative function of indicators focused on the elite AngloAmerican science university will be displaced. There are distinctive beneficiaries and powerful support for the single league table approach, despite its flaws. 
University rankings are marred by limiting, reductive and reifying qualities. These rankings are by most reasonable definitions "unfair". This is not a pathology of the techniques of ranking but of their social uses; whereby the processes of reduction and comparison, the creation of winners and losers, and the oversimplification of problems of complex judgement that are entailed, are the very rationales for the ranking process. Rankings reflect prestige and power, and rankings confirm, entrench and reproduce prestige and power. The particular systems in use tend to further the particular interests that do well within them. University rankings not only imagine and describe higher education in terms of Bourdieu's universal positional competition, they themselves are the outcome of the kind of struggle he describes over the terms in which social positionality is understood, described and fixed. Many institutions attempt to influence the system of classification and the contents of the data input in the rankings systems. In this some are more effective than others. As Bourdieu states in Distinction (1984):

Principles of division, inextricably logical and sociological, function within and for the purposes of the struggle between social groups: in producing concepts, they produce groups, the very groups which produce the principles and the groups against which they are produced (Bourdieu. 1984, p. 479).

In other words, there is a technical/social circularity about the rankings project: as in other such policy technologies that are designed to order and control the educational world, such as standardised testing in school systems. Categories such as university rank, as with the indicators that compose it help to shape the world of institutional hierarchy and social preference. Powerful social interests are assisted by these categories, and those interests return the favour, helping to shape or at least legitimate the categories in use. Those social interests are also shaped in the process of the use of ranking. And all this is now taking place on an international scale. Rankings provide a powerful support for the English-language university systems already leading higher education, perpetuating their global dominance, while also setting the objectives that those nations along with others must meet.

Global university rankings are tools of the imagination, discursive technologies and data sets whose time, it seems, has come. But rankings also frame imaginings and make the time. University rankings recall Foucault's famous words in The archacology of knowledge (1972), where he describes discourses, with Mozartian simplicity, as "practices that systematically form the objects of which they speak" (Foucault, 1972, p. 49). Rankings inculcate the idealised model of institution as a norm to be achieved and generalise the failure to achieve it. By installing at their apex a particular kind of elite institution (particular to mission and activity profile. to resources, to language of use and even, because of the preceding elements. to nation), in the university sector in which a status hierarchy once established sustains itself in the manner Bourdieu describes, rankings entrench the potency of the existing hierarchy. Global university rankings, appearing to all the world as a bold, open competitive struggle akin to a football championship, are a simple and brilliant device for reproducing the performative present into the future. 
Discourses of social status are primary in the sustaining of status and are all the more powerful when joined to the force of calculation. Winner-take-all markets in all sectors, not just universities, tend over time to concentrate power and resources at the top and become more steeply hierarchical (Frank \& Cook, 1995: Frank 2001). In ordering university performance as status, while shaping the distribution of resources (money, research concentrations) which are the means of competitive performance according to the status order, rankings help to ensure a continuous reinvestment in that order. Equally important is the function of rankings as a device of legitimation. University rankings install in the common mind the notion of competition in higher education as a level playing field, despite the lop-sided system settings. despite the rigged nature of the game, despite the relentless reproduction of the global university hierarchy. Rankings explain the failure of institutions to move up the league table in the manner of a football team, as their own failure of talent or volition, not as a failure of government policy or the outcome of gross world-wide inequalities in political economy and cultural clout.

Rankings originate in publishing of universities more often than state agencies but are near perfect tools for government in higher education. The routine of state management is to quell avoidable social tensions and reproduce the status quo while sustaining a thin sliver of space for changes of order within the elite, and a thinner space for upward mobility. Following the arguments of Hayek, and in response to the cultural disorders of the 1960s, neo-liberalism in education is less concerned about profitability than about social control. It wants to create the forms of economic competition without the openness and uncertainty, even anarchy, that would have accompanied a purer, less ordered market framework; and it seeks to do so on not just a national scale but a global scale. If neo-liberal government had not been given global university rankings, it would have had to invent them.

This paper has used the critique of neo-liberal government and the NPM as a system of relations of power, in order to interpret the purposes and outcomes of global university rankings, and to situate the rankings process within contemporary government and the patterns of global hegemony. Pierre Bourdieu is one of a number of theorists who provide useful resources for such an exercise. The chapter has sought to develop its critique while acknowledging salient features of the contemporary environment in higher education, including the accelerating moving of people. knowledge and ideas across borders; the growth in the role of market forces, especially in cross-border degrees; the prestige enjoyed by leading universities from the U.S.A. and (to a lesser extent) the U.K; and the openness and ambiguity of global relations. However, despite the efforts of global rankings systems to define a competitive educational order, the hierarchy is more open and relations are more unstable than is the case at the national level.

The production of global public goods such as knowledge, where exchange is free and takes place outside market relations, is at least as materially formative as is the production of global private goods such as status and earnings benefits. In taking the analysis further, it would be useful to conduct situated case studies (Deem, 2001) mapping the effects of rankings (and international competition more generally) in national systems and individual institutional strategies; and in 
supplementing the fashionable emphasis on competitive markets, to draw out the effects of contemporary practices of cooperation and collective production, within and between national borders, in structuring higher education (Marginson, 2007a).

\section{RTHTRENCS}

Altbach, p. (2006). The dilemmas of ranking International lligher Edhathon 1 ?.

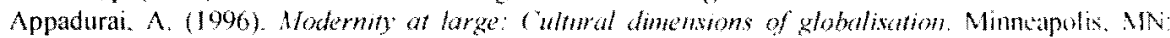
University of Mimesota Press.

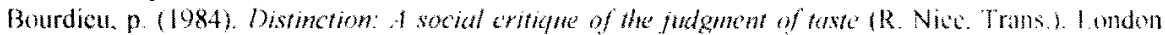
Routlcdge \& Kegan Paul.

Bourdieu. p. (1988). Homo Academicus (P. Colliur. Trans.) Cambridge Polity.

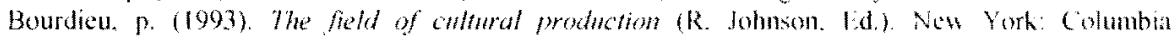
University Press.

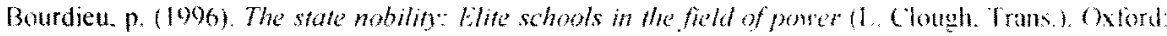
Polity.

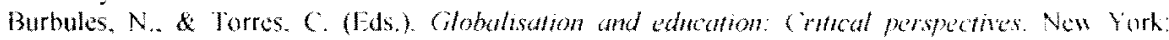
Routledge

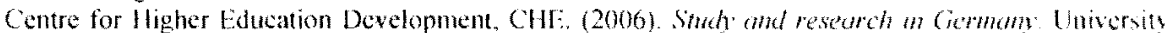
rankings, published in association with Die 7cit. Retrieved December 16. 2006, from htp / /www daad de/deutschland/studium/hochschulranking/04708.cn.htm

Centre for Science and Technology Studics, Leiden University. (CWTS). (2007). The leidion ranking. Retrieved June 20, 2007, from htt://www.cwts.n/cuvts/leidenRanking Wobsite hm

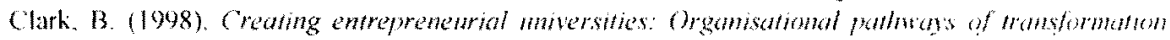
Oxford: Pergamon Press.

Deen. R. (2001). Globalisation. new managerialism, academic capitalism and entreprencurialism in

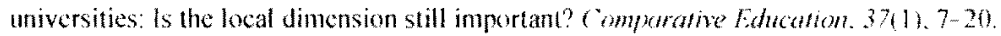

Dill, D., \& Soo, M. (2005). Academic quality, league tables, and public polic: A crosi-national analysis of university rankings. Higher tiduthom. $19,495-533$.

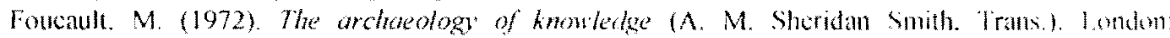
Tavistock

Frank. R. (2001). Higher education: The uttimate wimer-take-all market? In M. Ievlin \& I Mkyerson

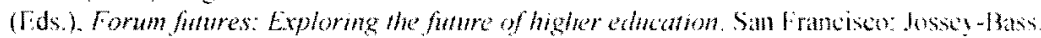

Frank, R. \& Cook p. (1995). The wimer-tokewll saciefy. New York: The like Press.

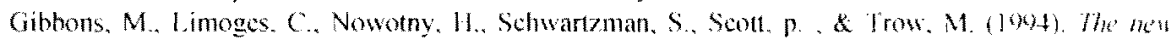

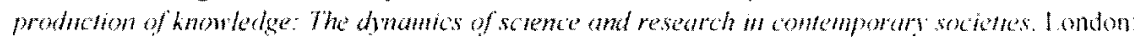
Sage.

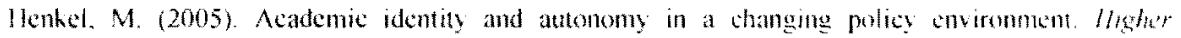
Edtuatom 19, 155-176.

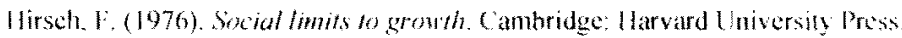

Institute for Sciontific Information. ISI-Thomson. (2006). Data on highly ciled researehers.

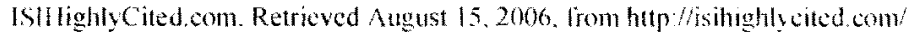

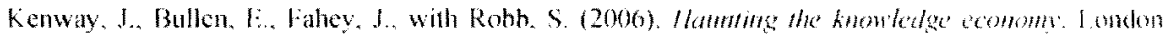
Runtledge.

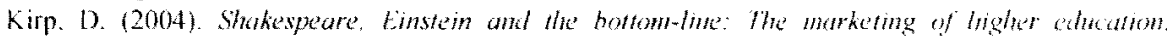
Cambridge. MA: llarvard University l'ress.

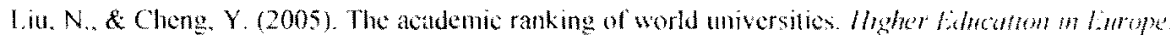
$30(2) .127 \cdots 136$

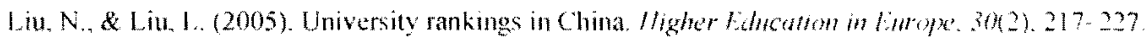

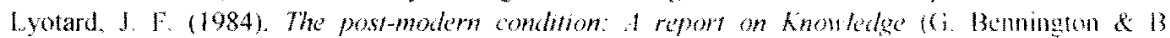
Massumi. lrans.). Mimuapolis, MN: University of Minnesota Press.

Marginson, S. (1097). Warket in thowion. Sydney. Allen and Unwin 
Marginson. S. (2007a). The public/private division in higher education: A global revision. Higher Education, $53,307-333$.

Marginson. $\$$. (2007b). Global position and position-laking: the case of Australta. Journal of Situdies in International Ealucation. $11(1) .5,32$.

Marginson. \$. (2007c). Prospects of higher education. Globalisaton, market competition. public goods and the future of the umversin: Rotterdam: Sense Publishers.

Marginson. S. (2008a). Global field and global imagining: Bourdicu and relations of power in worldwide higher education. British Journal of Sociology of Education, 29(3), 303-316.

Marginson. \$. (2008b). Hayekian neo-liberalism and academic self-determination. Educational Theory. $58(3), 269-287$

Marginson. S. \& Considine, M. (2000). The enterprase unversity: Power. governance and reimenton in Atstralia. Cambridge: Cambridge University Press.

Marginson, S. \& Mullis. M. (2001). "The dour opens and the tiger leaps": Theories and reflexivities of comparative education for a global millennium. Comparative Education Review, 45(4), 581-615.

Marginson, S. \& van der Wende, M. (2007). Globalsahon and higher education. Education Working Paper No. 8. Directorate of Education. (OECD. Paris: OFCD. Retrieved July 31. 2007, from http//www cshe unimelb.edu.au/people/staft pages/Marginson/OECD-Globalisationd HigherEd.pdf

McCormick. A.C. \& Zhao. C. (2005), Rethinking and reframing the Carnegie classification. Change, $57(5), 51-57$.

Musselin. C. (2005). European academic labour markets in transition. Higher Education. 49, 135-154.

Naidoo, R. (2004). Fields and institutional strategy: Bourdieu on the relationship between higher education. inequality and society. British Journal of Sociology of Educaion, 25(4), 446-472,

National Science Board. NSB. (2006). Science and engineering indicators 2004. Retrieved April 9. 2006. from htp:/www nsf.gov/statistics/seind04/

Nowotny. H. Scott. p. "\& Gibbons. M. (2001). Rethinking scrence: Knowledge and the public in an age of uncertaint Cambridge: Polity.

Organisation for Economic Cooperation and Development. OECD. (2006). Education at a glance Paris: Author.

Rhoads. R.. \& Torres. C. (2006). The umiversity, state, and market: The polincal economy of githalisation in the Americas. Stanford. CA: Stanford University Press.

Rose. N. (1999) Powers of freedom. Cambridge: Cambridge University Press.

Salmi. J. \& Saroyan. A (2006). League lables as policy instruments. Uses and misuses. OECD/IMIIF \& llochschulrektorenkonferenz. Germany. Workshop 4-5 December. Bonn. See Organisation for Eeonomic Cooperation and Development, Institutional Management in Higher Education program. Retrieved March 10. 2007, from hitp//www oecd.org

Shanghai Jiao Tong University Institute of Higher Education, SJTUIHE. (2007). Academic ranking of world wnversines. Retrieved June 20, 2007. from http:/ed sjtu.edu. cn/ranking htm

The Times Higher (2006). World university rankings. The Times Higher Education Supplement. Retrieved November 30,2006 , from www thes.co.uk [subscription required]

Usher. A. \& Savino, M. (2006). A world of difference: A global survey of unversity league tables. Retrievcd April 2, 2006. from http:/www educationalpolicy org

1.S. News and World Report. (2006). America's hest colleges. 2007 edition. Washington: USNWR.

Valimaa. 1. (2004). Nationalisation, localisation and globalisation in Finnish higher education. Higher Educahom. $76.27-54$.

Valimaa. J. (2005). Globalisation in the concept of Nordic Higher Education. In A. Arimoto, F. Huang. \& k. Yokoyama (Eds.), Glohalisation amd higher education. International Publications Series 9. Research Institute for Higher Education. Hiroshima University. Retrieved February 10. 2006. from http//en.rihe, hiroshima-u.ac.jp/pl_default 2.php?bid 63653

$\checkmark$ an der Wende. (2007a). European responses to glohal competrion in higher education. Symposium 'Crisis of the publics". Centre for Studies in Higher Fducation. UC Berkeley, 26-27 March Retrieved June 1. 2007. from http:/cshe berkeley cdu/events/crisis/docs/[password required] 


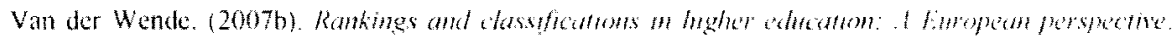
2nd I ciden lniversity International 53 mposium on Ranking $2 \&$. Fehuary.

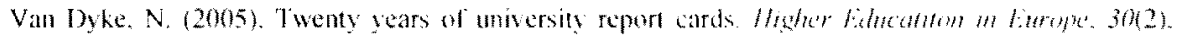
$103-125$

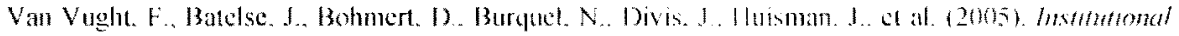

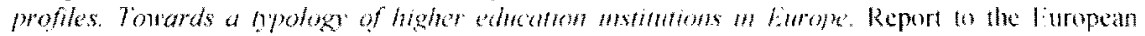

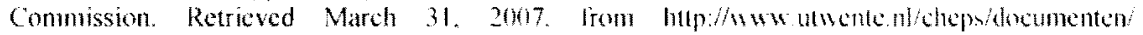
engroportosinstitutionalproliles put

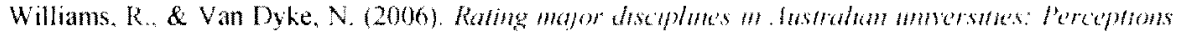
and reahty. Melboume: Melboume Instilute ol Applied licmomic and Social Research

\section{IURTIIIR RIANDINGS}

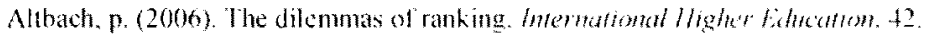

Bourdicu p. (1993). The foth of cahmal production lR. Johnson. lid.). New York Columbia University Press.

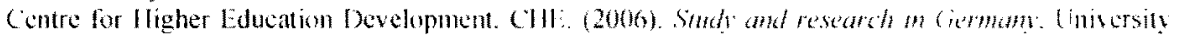
rankings. published in association with lic Zeit Retrievol Decomber 16. 20106. Irom htp:/www daad de/deutschland/studinn/hochschulranking/04768.cn hml

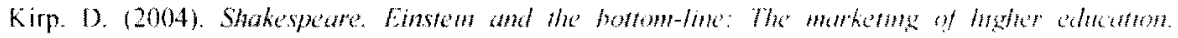
Cambridge, MA: llarvard liniversily Press.

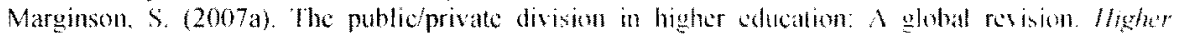
Edhothon, 53,307-333.

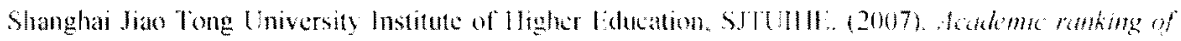

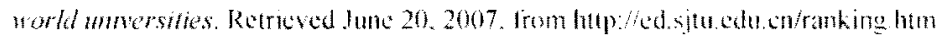

\section{Simon Marginson}

Centre for the Study of Higher Edtation

Univensty of Melboume, Australiat 


\section{University Library}

\section{- M M I E R R V A gateway to Melbourne's research publications}

Minerva Access is the Institutional Repository of The University of Melbourne

Author/s:

Marginson, SWM

Title:

University Rankings, Government and Social Order

Date:

2009

Citation:

Marginson, S. W. M. (2009). University Rankings, Government and Social Order. Simons, M (Ed.). Olssen, M (Ed.). Peters, M (Ed.). Re-Reading Education Policies. A Handbook Studying the Policy Agenda of the 21st Century, (1), pp.584-604. Sense Publishers.

Persistent Link:

http://hdl.handle.net/11343/30619 